\title{
Research on Cracking Control of Immersed Tube Tunnels Concrete by Pre-heating treatment
}

\author{
Fang $\mathrm{Yu}^{1, *}$, Chunlin Deng ${ }^{1}$, Zhibo Sheng ${ }^{1}$, Kangchen Wang ${ }^{2}$ and Shenyou Song ${ }^{2}$ \\ ${ }^{1}$ Key Laboratory of Durability Technology for Harbor and Marine Structure, Ministry of Communications, China \\ ${ }^{2}$ Shenzhen-Zhongshan Link Administration Center, Zhongshan, 528400, China.
}

\begin{abstract}
Herein, the pre-heating treatments are researched. With diversity of zone and temperature, highest average temperature of the section $10 \mathrm{~cm}$ below surface was $14.7^{\circ} \mathrm{C}$, which is lower than that of the concrete block. And the distance of $20 \mathrm{~cm}$ and $40 \mathrm{~cm}$ to surface of section, the temperature is $11.8^{\circ} \mathrm{C}$ and $9.8^{\circ} \mathrm{C}$, respectively. When the heating water of $60^{\circ} \mathrm{C}$, the increase of $48 \mathrm{~h}$ to $72 \mathrm{~h}$, the highest temperature is about $47.2^{\circ} \mathrm{C}$ and $49.6^{\circ} \mathrm{C}$.
\end{abstract}

\section{Introduction}

With the development of marine structures, especially in China. The Immersed tubes have been built in seacrossing projects. However, tubes that casted onsite or prefabricated with full-section casting are facing a problem of cracking control in constructions. The concrete blocks are pouring adopted, it is less impacted by climate and better curing condition, but concrete easily presented cracks in the old-new interfacial region during the construction, of which cracks occurred longitudinally and transversely were illustrated in Figure 1.



Fig. 1. Cracks occurred in interfacial region

The cracks caused by the external restrain of old sections, in new sections, and the shrinkage of tubes mainly stem from shrinkage of concrete cooling and drying shrinkage. Moreover, the shrinkage of concrete after $14 \mathrm{~d}$ continues to be happened, the temperature of concrete dropped and contraction unfinished. According to the simulations and literatures, the cracks caused by temperature difference onto surface is less, but the possibility of cracking caused by constraint of new and old concrete is greater.

Therefore, the old concrete should be heated, and when the temperature of the new concrete rises to the peak, the two should be cooled at the same time to achieve the synergistic shrinkage effect. It is important to study on the distribution of pipe and heating range of pipe, toward to the implementation of heating measures for immersed tubes and development of countermeasures.

\section{Experiment}

\subsection{Preparation of Concrete block}

One concrete section with size of $5.0 \mathrm{~m} \times 3.0 \mathrm{~m} \times 1.5 \mathrm{~m}$ block is to be poured. The temperature and deformation of the internal section of concrete are to be monitored to analyse the distribution and varied volume of internal temperature field, and verify the performance of concrete. Temperature monitori shall be carried out after the concrete section 1 is poured. When the concrete drops to normal temperature, pre-heating tests shall be carried out in three areas (A, B and C zone), to study the variation trend of internal temperature field and deformation amount under the pre-heating condition.

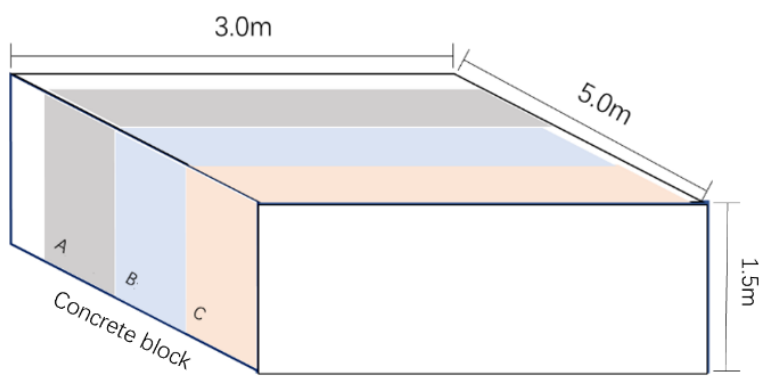

Fig. 2. Schematic diagram of concrete block

Before casting, Temperature sensors embedded in the formwork monitor, of which monitor the specific location including: upper surface $(5 \sim 10 \mathrm{~cm}$ from the upper surface

$\overline{{ }^{*} \text { Corresponding author: yfang1@eccc4.com }}$ 
of concrete), lower surface $(5 \sim 10 \mathrm{~cm}$ from the lower surface of concrete), component center, geometric center of water pipe section, etc. And Water pipes and temperature monitoring points in zone are shown in the figure 3 .

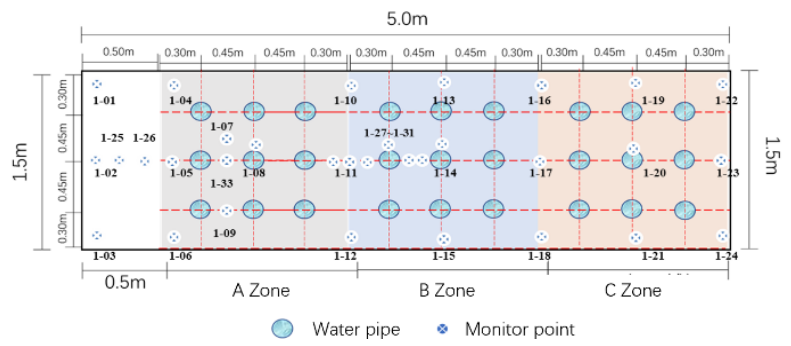

Fig. 3. Schematic diagram of Water pipes and temperature monitoring points

\subsection{Experimental process}

The heating process is as follows: After heating area A zone for $5 \mathrm{~d}$, the heating time of A and B Zone is $5 \mathrm{~d}$. Finally, the heating time of region $\mathrm{A}$, Region $\mathrm{B}$ and region $\mathrm{C}$ is also $5 \mathrm{~d}$. The average water temperature of the initial inlet is stable at $60^{\circ} \mathrm{C}$, and the outport temperature of water is about $2 \sim 3^{\circ} \mathrm{C}$ lower than that of inlet. According to the temperature sensor embedded in the concrete, the internal temperature change of different zones under different heating time are monitored, and the average temperature of different sections can be calculated. The section deformation of the concrete model was measured by hook embedded in the upper surface of concrete block everyday and deformation of blocks was analysed.

\section{Experiment}

\subsection{Temperature and deformation of different section in temperature-fall period}

The distribution and monitoring results of monitoring points for upper, central and lower temperatures of concrete at different locations are shown in figure 4 . The formwork on the right side of the concrete block was removed after $40 \mathrm{~h}$, and the others were not removed. After concrete poured, the top surface of concrete adopted the curing with covered of plastic film and wet geotechnical cloth.

In the hydration stage of concrete, the heat generated by cement hydration can be transmitted to the environment through the steel formwork, which has great heat dissipation, Thus, the maximum temperature reached by the upper part of concrete is low. Due to the good thermal conductivity of the steel formwork, the ambient temperature reaches the peak of a day, the steel formwork will deliver heat conduction to the concrete. Therefore, the upper surface temperature of concrete could fluctuate, corresponding with the ambient temperature. After the concrete center reaches the maximum temperature, when the ambient temperature is the highest, the concrete upper surface temperature exceeds the central temperature.
The maximum of core temperature of sections reach $74.5^{\circ} \mathrm{C}$ after $34 \mathrm{~h}$ pouring, and the temperature difference in the inner surface of concrete does not exceed $20^{\circ} \mathrm{C}$. The difference between the upper surface temperature and the ambient temperature reached the maximum after $29 \mathrm{~h}$, of which maximum temperature difference was about $34.9^{\circ} \mathrm{C}$. After $68 \mathrm{~h}$, the difference between the upper surface temperature and the ambient temperature began to be less than $20^{\circ} \mathrm{C}$. The temperature variation was illustrated in figure 4.


Fig. 4. Temperature variations of concrete

\subsection{Temperature and deformation of different section in heating period}

\subsection{1 inner temperature in concrete}

After concrete heated, the monitoring results are shown in Figure 5. The core temperature in A zone remained stable after 28 hours of heating, the core temperature in B zone remained stable after 30 hours, and the core temperature in $\mathrm{C}$ zone remained stable after 34 hours. It can be found that with the increase of the hot water area of concrete and the extension of the heating path, the time needed for the stability of the temperature rise of core concrete will be extended. When the central temperature of concrete in different areas tends to be stable. Therefore, under the concrete block of size, the increase of the heating area are not reduce the core temperature, but only extends the time required for temperature stabilization.

The heating time and temperature at different measuring points between water pipes are shown in Table 1. The measurement points 1-07 are located at the core of four water pipe sections and are mainly affected by the heating of four water pipes. The measurement points 1-33 are located in the middle of water pipes, and mainly affected by the hot water heating of two water pipes. The distance between the measuring point 1-07 and the core water pipe in A zone is about $32 \mathrm{~cm}$, the distance between the measuring point $1-33$ and the central water pipe in 
region $\mathrm{A}$ is about $21 \mathrm{~cm}$, and the distance between the measuring point 1-07 and the water pipe is further. From the two points temperature monitoring results, the temperature variation trend and magnitude of the measuring points 1-07 and 1-33 are similar. The distance between 1-07 and the heating water pipe is relatively far, but the number of heating water pipes makes up for the disadvantage of the distance.1-09 is located in the middle of two water pipes at the bottom of concrete. Although the rising trend of temperature is similar to that of the measuring point $1-33$, the concrete has good heat dissipation due to its contact with the ground. When the temperature tends to be stable, the maximum temperature is $6^{\circ} \mathrm{C}$ lower than that of $1-33$.

Table 1. Temperature in different points

\begin{tabular}{|c|c|c|c|}
\hline No. & $\begin{array}{c}\text { Distance to } \\
\text { pipe/cm }\end{array}$ & $\begin{array}{c}\text { Stable } \\
\text { time/h }\end{array}$ & $\begin{array}{c}\text { Stable } \\
\text { temperature } /{ }^{\circ} \mathrm{C}\end{array}$ \\
\hline $1-08$ & 3 & 54 & 58 \\
\hline $1-33$ & 21 & 60 & 56 \\
\hline $1-07$ & 32 & 60 & 56 \\
\hline $1-09$ & 32 & 84 & 50 \\
\hline
\end{tabular}

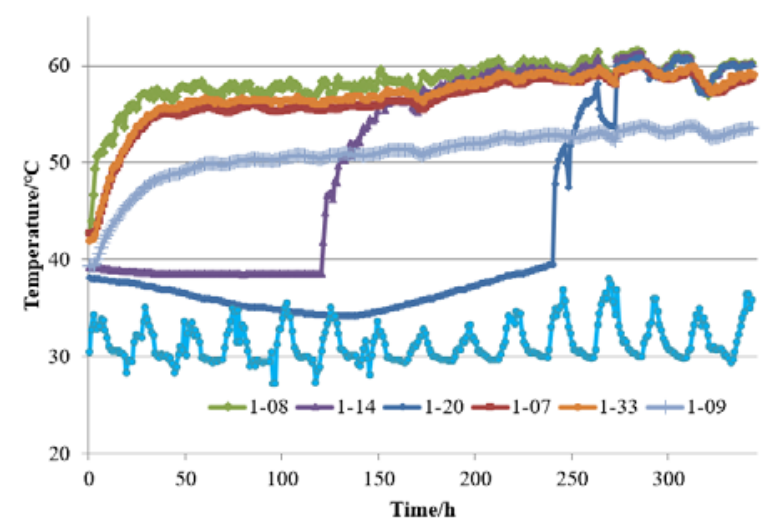

Fig. 5. Temperature variations of different points in concrete

\subsection{2 influence range of heating by pipe}

The heating stability time and temperature at different horizontal positions from the heating pipe are shown in Table2, and the concrete temperature monitoring is shown in Figure 6. According to the temperature monitoring results, the closer the distance is to the water pipe, the shorter the time needed for the heating temperature to reach the temperature. When the distance exceeds $45 \mathrm{~cm}$, the time for the heating temperature to reach the stability will not increase with the increase of the distance. After heating, the surrounding concrete is heated, and the temperature distribution of the heated concrete has a certain gradient. The temperature gradient of concrete is linearly distributed within $15 \sim 90 \mathrm{~cm}$ from the horizontal position of water pipe. When the distance exceeds $90 \mathrm{~cm}$, the heating pipe has no obvious thermal effect on the concrete, the temperature of different points is illustrated in table2.
Table 2. Temperature in different points

\begin{tabular}{|c|c|c|c|}
\hline No. & $\begin{array}{c}\text { Distance to } \\
\text { pipe/cm }\end{array}$ & $\begin{array}{c}\text { Stable } \\
\text { time/h }\end{array}$ & $\begin{array}{c}\text { Stable } \\
\text { temperature } /{ }^{\circ} \mathrm{C}\end{array}$ \\
\hline $1-27$ & 15 & 76 & 52 \\
\hline $1-11$ & 30 & 83 & 48 \\
\hline $1-28$ & 45 & 91 & 46 \\
\hline $1-29$ & 60 & 91 & 43 \\
\hline $1-30$ & 75 & 92 & 42 \\
\hline $1-31$ & 90 & 92 & 40 \\
\hline
\end{tabular}

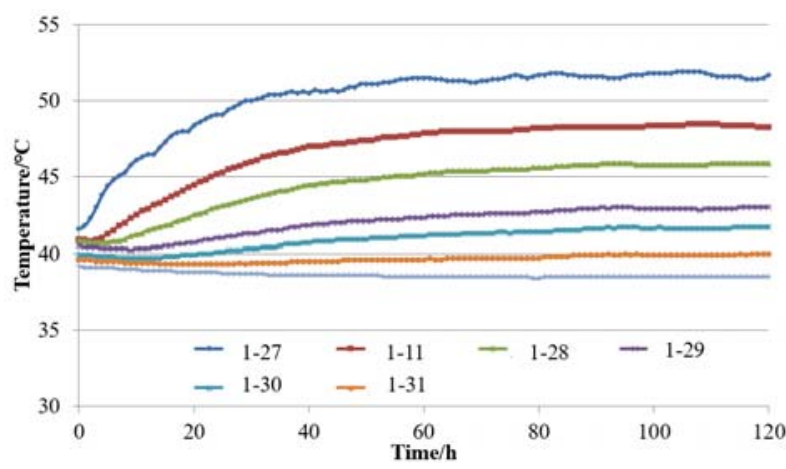

Fig. 6. Temperature variations of different points in concrete

The temperature field distribution at different locations of pipes with different heating times are shown in fig 6. After the temperature stabilizes, the temperature field distribution is shown in fig 7 . When heated for $12 \mathrm{~h}$ and $24 \mathrm{~h}$, the concrete isotherm at $50{ }^{\circ} \mathrm{C}$ was $10 \mathrm{~cm}$ away from the water pipe; when heated for $48 \mathrm{~h}$, the range of $50{ }^{\circ} \mathrm{C}$ began to expand to $15 \mathrm{~cm}$; when heated for $72 \mathrm{~h}$, the isotherm at $50{ }^{\circ} \mathrm{C}$ stabilized to $20 \mathrm{~cm}$. When heated for $12 \mathrm{~h}$, the isotherm at $45^{\circ} \mathrm{C}$ was $22 \mathrm{~cm}$ away from the water pipes. With the heating time of $24 \mathrm{~h}, 48 \mathrm{~h}$ and $72 \mathrm{~h}$, the isotherm expanded to $30 \mathrm{~cm}, 44 \mathrm{~cm}$ and $50 \mathrm{~cm}$, respectively, start to stabilize. The range of isotherm was not significantly expanded after further heating. When heating for $12 \mathrm{~h}$, the isotherm at $40{ }^{\circ} \mathrm{C}$ was $42 \mathrm{~cm}$ from the water pipe, and when heating for $24 \mathrm{~h}, 48 \mathrm{~h}$ and $72 \mathrm{~h}$, the isotherm was expanded to $79 \mathrm{~cm}, 80 \mathrm{~cm}$ and $89 \mathrm{~cm}$ respectively, and the range of the isotherm was further expanded to a small extent. From the change of temperature field, the temperature range of $50^{\circ} \mathrm{C}$ and above after concrete heating is the smallest, and with the extension of heating time, the expansion area is the smallest, but the actual stable temperature is the shortest. The temperature range of $40 \sim 45^{\circ} \mathrm{C}$ is the largest. After heating for $24 \mathrm{~h}$, the influence range will be larger, but the influence range of further heating will not increase much. The influence range of $45 \sim 50^{\circ} \mathrm{C}$ is between them. With the extension of heating time, the expanded area also increases greatly. From the perspective of heating effect, the influence of hot water on the thermal range of concrete can be maximized by heating for $24 \mathrm{~h}$. In the heating stage, the temperature field of concrete shows exponential distribution within the range of $0 \sim 90 \mathrm{~cm}$ from water pipe. When the heating is stable, the concrete temperature field 
shows a linear distribution within the range of $15 \sim 90 \mathrm{~cm}$ from the water pipe.
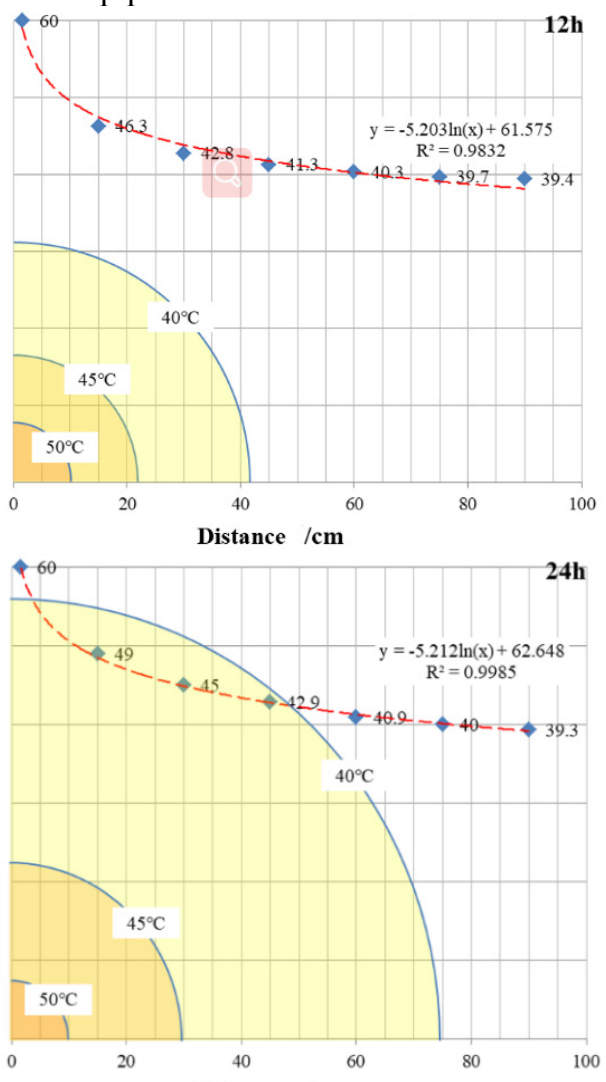

Distance $/ \mathrm{cm}$
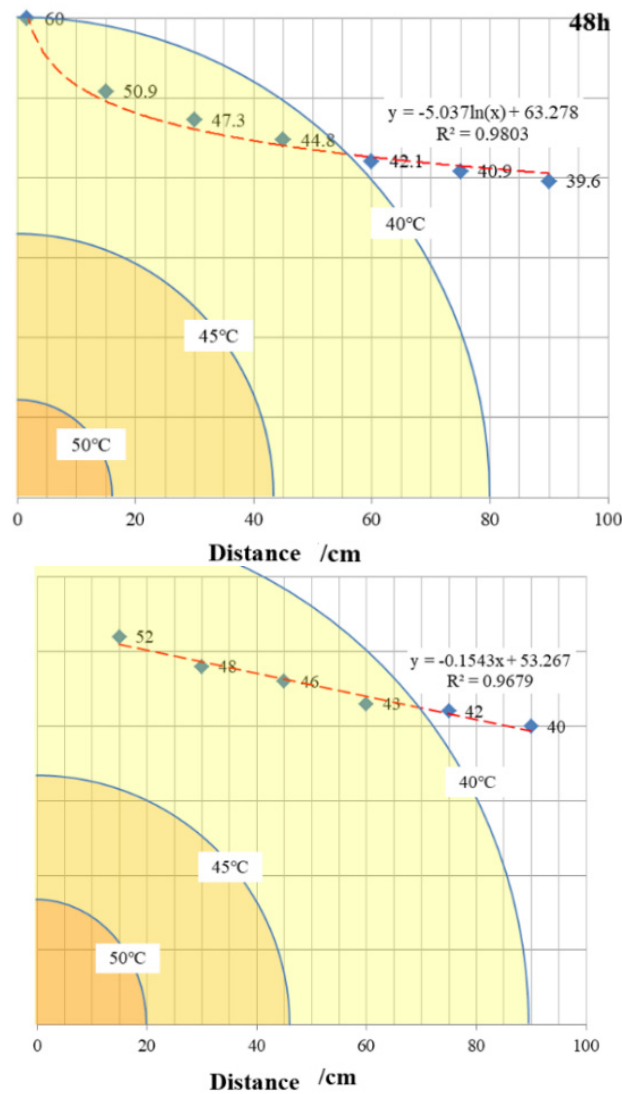

Fig. 7. Temperature variations of different points in range

\section{Conclusions}

The highest average temperature of the section $10 \mathrm{~cm}$ to the left was $14.7^{\circ} \mathrm{C}$ lower than that of the block. The highest average temperature of the section $10 \mathrm{~cm}$ to the left was $14.7^{\circ} \mathrm{C}$ lower than that of the plain concrete section; the lowest average temperature was $11.8^{\circ} \mathrm{C}$ lower than that of the template $20 \mathrm{~cm}$; the lowest average temperature was $9.8^{\circ} \mathrm{C}$ lower than that of the template $40 \mathrm{~cm}$; the concrete temperature within $50 \mathrm{~cm}$ at the end was significantly lower than the internal temperature. Therefore, appropriate curing conditions, such as heat preservation, can be taken into consideration in the actual construction of immersed pipe joint to maintain the original temperature field of old concrete and reduce the risk of restricted cracking.

\section{Acknowledgement}

This study is supported by the Key-Aera Research and Development Program of Guangdong Province (2019B111106002)

\section{References}

1. Abed, F., H. El-Chabib, and M. Alhamaydeh. "Shear characteristics of GFRP-reinforced concrete deep beams without web reinforcement." Journal of Reinforced Plastics \& Composites 31. 16 (2012): 1063-1073.

2. In, Chi Won, et al. "A Fully Non-contact, AirCoupled Ultrasonic Measurement of Surface Breaking Cracks in Concrete." Journal of Nondestructive Evaluation 34.1(2015):272.

3. Beckenbach, J. R. "Tomato production on the sandy soils of south Florida." Journal of Functional Materials 43.13(2012):1704-1707.

4. Groth, Patrik. "Cracking in concrete: crack prevention with air-cooling and crack distribution with steel fibre reinforcement." Lule Tekniska Universitet (1996).

5. Vasconez, Rosa M., A. E. Naaman, and J. K. Wight. "Behavior of HPFRC Connections for Precast Concrete Frames Under Reversed Cyclic Loading." Pci Journal 43.6(1998):58-71. 